\title{
SUBSÍDIOS TEÓRICOS E PRÁTICOS PARA A ELABORAÇÃo DE TESTES DE CONSCIÊNCIA LINGUÍSTICA
}

\author{
Aline Lorandi é doutora em Letras e professora da Universidade do Vale do Rio dos Sinos. \\ E-mail: alinelorandi@gmail.com \\ Débora Mattos Marques é graduanda pela Universidade Federal do Pampa. \\ E-mail: deboramattos@gmail.com
}

\section{Resumo \\ Este trabalho objetivou verificar relações entre consciência fonológica e morfológica em crianças brasileiras. Os testes abrangem níveis de acesso consciente E2 e E3 (KARMILOFF-SMITH, 1992; LORANDI; KARMILOFF-SMITH, 2012). A análise dos níveis mostra que a consciência morfológica e a fonológica seguem trajetórias ligeiramente diferentes no desenvolvimento das crianças investigadas, de modo especial com relação ao nível E3.}

Palavras-chave: Testes de consciência linguística; Modelo RR; Fonologia; Morfologia; Ensino em séries iniciais.

\begin{abstract}
This study aims to verify possible relations between phonological and morphological awareness in Brazilian children. The tests involve levels of conscious access E2 and E3 (KARMILOFF-SMITH, 1992; LORANDI; KARMILOFF-SMITH, 2012). The analysis of the levels shows us that morphological and phonological awareness follow slightly different developmental trajectories in the studied population, especially with regard to the level E3.

Key words: Linguistic awareness tests; RR model; Phonology; Morphology; Teaching for early grades.
\end{abstract}

\section{1) INTRODUÇÃO}

A metodologia científica é uma área em constante desenvolvimento, visto que o investimento em tecnologias cada vez mais refinadas tem permitido aos pesquisadores novos e mais ousados insights sobre os mais diversos âmbitos das ciências. No caso deste trabalho, pensar em uma metodologia capaz de fornecer dados de consciência morfológica e fonológica é importante, uma vez que o debate acerca do que podem ser considerados dados relevantes e sobre em que consiste a consciência linguística é profícuo e tem sido tema de diversos trabalhos há várias décadas. Essas questões serão exploradas neste trabalho.

Pratt e Grieve (1984) apontam que uma das difíceis tarefas relacionadas ao estudo da consciência linguística é a decisão sobre o que podem consistir em dados pertinentes. Em seu entendimento, assim como nas concepções desenvolvidas neste trabalho, essa decisão precisa ser amparada em um modelo teórico que, por sua vez, deverá abordar de modo adequado e preciso o que é a consciência linguística. Em outras palavras, noções diferentes sobre o que é consciência podem levar a diferentes deliberações sobre dados.

Em 1978, Clark e também Slobin empreenderam esforços para mostrar que dados iniciais de consciência linguística aparecem cedo na fala da criança, com observações, correções ou questionamentos sobre sua própria fala e a fala dos que a rodeiam. Algumas vezes, a sensibilidade à consciência pode ser observada em brincadeira com a linguagem. Slobin traz o exemplo de uma menina de $3 ; 4$, que reformula sua própria fala diversas vezes até encontrar o que entende ser a forma correta: 
Some friend of mine gave it to me. A girl friend gave it to me. A girl of my friend gave it to me. A girl my friend gave it to me. Self-correction: You didn't give me a fork. You didn't gave me a fork (SLOBIN, 1978, p. 49). ${ }^{1}$

Em outro exemplo, provido em LORANDI (2011b), a criança mostra, por meio da marca de gênero gramatical, seu entendimento de como a morfologia flexional funciona, generalizando a regra a uma palavra que não seria alvo de flexão:

O pai (referindo-se ao time de futebol "Grêmio") diz:

- Tu é do Grêmio.

F. $(2 ; 6)$ corrige:

- Tu é Grêmio. Eu sou Grêmia.

Exemplos como esse são comuns na fala das crianças. Todavia, nem todos os autores os consideram como evidências do que podem constituir rudimentos da consciência linguística. A questão da idade de emergência dos dados também representa um fator importante tanto para a definição de consciência linguística como para o que pode ser tomado como indício de seu surgimento. Tunmer e Herriman (1984) identificam três visões diferentes sobre esse assunto: a primeira delas acredita que a consciência linguística desenvolve-se juntamente ao processo de aquisição da linguagem, de modo a ajudar nesse processo, bem como a aquisição em si também auxiliaria no desenvolvimento da consciência; a segunda visão entende que a consciência linguística apenas emerge por volta de 6 a 8 anos, como fruto do desenvolvimento de outras habilidades; enquanto uma terceira visão pondera que a consciência linguística somente é desenvolvida após a introdução da criança ao ensino formal e como resultado do que é ensinado (como a leitura e a escrita).

Partindo do pressuposto de que somente é possível tomar decisões com relação a dados de consciência linguística à luz de modelos teóricos eficazes na explicação do que vem a ser esse fenômeno, o presente trabalho busca oferecer subsídios para a reformulação de um teste de consciência morfológica, a partir do que fora desenvolvido por Lorandi (2011a), bem como para a ampliação de um teste de consciência fonológica, de Moojen et al. (2003), de modo a que se captem as sutilezas que os diversos níveis de consciência propostos pelo modelo de Redescrição Representacional são capazes de evidenciar. Assim, procede-se à explanação desses níveis.

\section{2) O MODELO DE REDESCRIÇÃO REPRESENTACIONAL E A CONSCIÊNCIA LINGUÍSTICA}

Na perspectiva teórica adotada neste estudo, a consciência linguística pode ser verificada em quatro níveis de redescrição representacional de gradual desenvolvimento, pelos quais a informação implícita na mente torna-se, com o passar

\footnotetext{
${ }^{1}$ Tradução destas autoras: Alguma amiga minha me deu. Uma amiga minha me deu. Uma menina de minha amiga me deu. Uma menina minha amiga me deu. Autocorreção: Você não me deu um garfo. Você não me deu um garfo (com dupla marcação de tempo passado em inglês, sem tradução possível em português).
} 
do tempo, conhecimento explícito para a mente, possibilitando sensibilidade, acesso consciente e verbalização de conhecimentos em níveis que vão além do procedimental. Esse modelo foi proposto por Annette Karmiloff-Smith $(1986,1992,1994)$ e oferece uma alternativa aos estudos sobre consciência que abarcam apenas o nível implícito ou o explícito, captando sutilezas do desenvolvimento que os modelos dicotômicos não possibilitam ou não explicam adequadamente (LORANDI; KARMILOFF-SMITH, 2012, 2014; LORANDI et al., 2013). Sob esse recorte teórico, uma proposta de conceito de consciência linguística foi desenvolvida (LORANDI, 2011, p. 215), em que consiste no alcance de determinados níveis de representação mental, nos quais o conhecimento está em um formato no qual é possível:

- mostrar sensibilidade aos recursos da língua (Explícito 1);

- trabalhar em tarefas offline (Explícito 2);

- pronunciar-se sobre o conhecimento (Explícito 3).

Sob esse conceito, de acordo com os pressupostos deste trabalho, a consciência fonológica poderia ser entendida como o alcance de determinados níveis de representação mental, em que gradualmente o conhecimento fonológico em nível de sílaba e em nível de fonema é redescrito, tornando-se gradualmente mais flexível e manipulável, tomando sílaba, fonema e elementos suprassegmentais como objetos de análise, em oposição ao seu uso procedimental para produção e compreensão de palavras e sentenças. Diferentes habilidades cognitivas relativas às especificidades de cada nível são possíveis, conforme os exemplos de Lorandi (2011b, p. 215):

\begin{tabular}{|c|l|}
\hline Nível de redescrição representacional & \multicolumn{1}{|c|}{ Exemplos $^{2}$} \\
\hline Implícito (procedimental) & $\begin{array}{l}\text { É possível verificar o nível implícito em } \\
\text { momentos de uso da fala, sem reflexão sobre } \\
\text { ela ou, então, quando se pede a uma criança } \\
\text { que produza um fonema que ela ainda não } \\
\text { conhece, e ela o produz, sem necessariamente } \\
\text { tê-lo em seu sistema, mas por imitação. }\end{array}$ \\
\hline recursos fonológicos da língua) & $\begin{array}{l}\text { Nível da sílaba: M. e A.C. (2;4) estão } \\
\text { tomando café da manhã, M. pediu pão com } \\
\text { geléia, mas apontou para a manteiga. M. } \\
\text { disse que era 'geléia', A. C. disse que era } \\
\text { 'manteiga'. M. apontou para o rótulo e disse: } \\
\text { aqui está escrito ge-léi-a. A. C. respondeu: } \\
\text { não! man-te-ca!! } \\
\text { Nível do fonema: A.C. (2:6) costuma falar } \\
\text { "pilme” em vez de “filme”. Então seus pais } \\
\text { perguntam: } \\
\text { - Você quer ver um 'pilme’? }\end{array}$ \\
\hline
\end{tabular}

\footnotetext{
${ }^{2}$ A maioria dos exemplos são apresentados em Lorandi (2011b) e constituem dados anedóticos apenas para fim de ilustração.
} 


\begin{tabular}{|l|l|}
\hline & $\begin{array}{l}\text { Ela responde, gritando, para os pais } \\
\text { entenderem: } \\
\text { - Não é ['piw.mi], é ['piw.mi]! } \\
\text { (repetindo a palavra da mesma forma, uma } \\
\text { vez que não consegue produzir de outro } \\
\text { jeito). }\end{array}$ \\
\hline Explícito 2 (acesso consciente) & $\begin{array}{l}\text { Tarefas que envolvam processamento offline, } \\
\text { como as tipicamente apresentadas em testes } \\
\text { de consciência fonológica. } \\
\text { Nível da sílaba: tarefas de elisão silábica, } \\
\text { como: vou dizer uma palavra em pedaços e } \\
\text { quero que me digas que palavra eu falei: [ma] } \\
\text { (pausa) [sa]. Que palavra eu disse? A criança } \\
\text { responde: ['ma.sa]. } \\
\text { Nível do fonema: vou dizer uma palavra em } \\
\text { pedaços ainda menores. Quero que me digas } \\
\text { que palavra eu falei: [f] [a] [d] [a]. Que } \\
\text { palavra é essa? A criança responde: ['fa.da]. }\end{array}$ \\
\hline relato verbal) & $\begin{array}{l}\text { Nível do fonema3: durante a realização de } \\
\text { um teste, em que deveria lidar com a } \\
\text { pseudopalavra 'mafata', um menino da 2a } \\
\text { série fez o comentário: "uma faca e mafata } \\
\text { são parecidas. É só trocar o 't' por um 'c'”. }\end{array}$ \\
\hline (acesso consciente
\end{tabular}

Quadro 1: Exemplos de níveis de consciência fonológica, de acordo com o modelo RR.

Fonte: os autores.

A consciência morfológica, por sua vez, seria o alcance de determinados níveis de representação mental, em que gradualmente os traços estruturais da morfologia da língua, em nível de flexão, de derivação e de composição, nominal e verbal, são redescritos, tornando-se gradualmente mais flexíveis e manipuláveis, de modo que se distingam do simples uso do sistema linguístico para produzir e compreender palavras e sentenças. Sob a perspectiva do modelo RR, o desenvolvimento do conhecimento morfológico poderia evidenciar os diferentes níveis de redescrição representacional, de acordo com o quadro 2 .

\begin{tabular}{|c|l|}
\hline Nível de redescrição representacional & \multicolumn{1}{|c|}{ Exemplos } \\
\hline Implícito (procedimental) & $\begin{array}{l}\text { Primeiros usos corretos de formas verbais } \\
\text { irregulares, que poderiam ser entendidos } \\
\text { como formas não analisadas, como “eu fiz”. }\end{array}$ \\
\hline
\end{tabular}

${ }^{3}$ Como o nível do fonema é mais difícil que o da sílaba, e o nível Explícito 3 mais oneroso cognitivamente que os demais, entende-se que um exemplo em nível de sílaba seja dispensável para os fins deste projeto. 


\begin{tabular}{|c|c|}
\hline $\begin{array}{l}\text { Explícito } 1 \text { (sensibilização aos } \\
\text { recursos fonológicos da língua) }\end{array}$ & $\begin{array}{l}\text { A menina F., (2;9), olhando para uma pedra } \\
\text { e, em seguida, para o primo, Pedro, comenta: } \\
\text { - Pedra... Pedro... } \\
\text { Outro exemplo são as supergeneralizações de } \\
\text { formas verbais irregulares, tais como "eu } \\
\text { fazi", que evidenciam uma sensibilidade, } \\
\text { uma análise interna do sistema de flexão } \\
\text { verbal, tais como abordadas por Lorandi } \\
(2007,2011 \text { a). }\end{array}$ \\
\hline Explícito 2 (acesso consciente) & $\begin{array}{l}\text { Tarefas que envolvam processamento } \\
\text { offline } 4 \text {, como as tipicamente apresentadas } \\
\text { em testes de consciência morfológica. Um } \\
\text { exemplo de Lorandi (2011a) evidencia o } \\
\text { acesso consciente ao conhecimento } \\
\text { morfológico: } \\
\text { O pesquisador questiona: "um flopo pequeno } \\
\text { é um...?" } \\
\text { A criança responde: "flopinho". }\end{array}$ \\
\hline $\begin{array}{l}\text { Explícito } 3 \text { (acesso consciente e } \\
\text { relato verbal) }\end{array}$ & $\begin{array}{l}\text { V. - Quem é essa? } \\
\text { I. (6;5) - Essa é a bailarina. } \\
\text { Ela dança balé } \\
\text { Na ponta do pé } \\
\text { V. - Olha! Balé e pé rimaram! } \\
\text { I. - Claro, né! Por isso eu disse "do } \\
\text { pé" e não "dos pés!" } \\
\text { Outro exemplo: } \\
\text { O pesquisador questiona: Se tu ouvisses uma } \\
\text { criança dizer "eu fazi um bolo", dirias que } \\
\text { está certo ou não? Por quê? Como corrigir? } \\
\text { (caso a resposta fosse "está errado"). } \\
\text { O. (7:8): Errado. Porque é "eu faço" um bolo, } \\
\text { não "eu fazi" um bolo. }\end{array}$ \\
\hline
\end{tabular}

Quadro 2: Exemplos de níveis de consciência morfológica, de acordo com o modelo RR. Fonte: os autores.

À luz do modelo RR, não apenas os dados de sensibilidade aos recursos da língua ganham visibilidade e lugar fora do alcance do "implícito", como também é possível distinguir respostas que utilizem o conhecimento por meio do acesso consciente da reflexão, explanação verbal sobre esse conhecimento, entendido pelo

\footnotetext{
${ }^{4} \mathrm{O}$ processamento offline requer que dados de uma tarefa sejam mantidos na mente enquanto se trabalha com eles para, então, produzir-se uma resposta.
} 
modelo como níveis diferentes. De modo a evidenciar todos esses níveis, os testes apresentados neste estudo apresentam diferentes tipos de tarefa.

\section{3) TESTE DE CONSCIÊNCIA MORFOLÓGICA- PRIMEIRA VERSÃO}

A presente pesquisa teve origem na tese de Lorandi (2011a), que buscou verificar dados de consciência morfológica em crianças, com testes de derivação, extração de base e flexão de palavras inventadas, além de um teste de julgamento de palavras. Todos os testes foram realizados com pseudopalavras, criadas a partir dos templates mais comuns do português brasileiro. Analisando os dados obtidos, três principais tipos de respostas dadas pelas crianças foram reconhecíveis: respostas relacionadas à morfologia (que eram as esperadas), à semântica (buscando um sentido para as palavras inventadas) e à fonologia (apresentando aproximação de sons iniciais), mostrando que algumas crianças lidavam com as palavras inventadas de maneira distinta ao que diz respeito à consciência fonológica e morfológica. As respostas ligadas à fonologia geraram uma nova pesquisa sobre a relação entre consciência fonológica e consciência morfológica; as ligadas à semântica motivaram a reformulação do teste.

Os testes de Lorandi (2011a) tinham por objetivo verificar os níveis de processamento mental de crianças, a partir do Modelo RR. Foram realizados com 84 crianças, com idades entre 3:4 e 10:11.

O Teste 1 buscava a derivação a partir de três pseudopalavras: "flopo", "segor" e "mafata". As questões eram as expostas em (1):

(1) Questões do Teste 1 (LORANDI, 2011a)

a. Uma pessoa que lida com flopos/segores/mafatas é um

b. Um flopo/segor/mafata pequeno(a) é um(a)

c. Um flopo/segor/mafata grande é um(a)

d. Um flopo/segor/mafata muito grande é um(a)

e. Um lugar cheio de flopos/segores/mafatas é um(a)

f. Uma pessoa cheia de flopos/segores/mafatas está

O Teste 2 apresentava a história de um bichinho chamado Winki. Nesse teste havia questões para extração de base e também questões de flexão com pseudopalavras.

(2) Exemplos de questões do Teste 2 (LORANDI, 2011a)

“(...) Imagine que esses dias ele contou que conheceu um zoque. Viu zoquinhos e zocões. $\mathrm{O}$ que significa zoquinho? . E zocão? . Ele andou muitos quilômetros e entrou em uma zocaria. O que significa zocaria? ." (extração de base)

“ (...) Winki diz que nas viagens ele mila muito. Se ele mila muito, ontem ele também ". (flexão) 
No Teste 3 foram apresentadas para as crianças o que chamamos de formas morfológicas variantes $^{5}$ (LORANDI, 2007), com dados obtidos de crianças, para julgamento de formas verbais, seguido de explicitação do conhecimento do informante sobre seu próprio julgamento.

\section{(3)Exemplo de questão do Teste 3 (LORANDI, 2011a)}

Vamos brincar de professor(a). Se tu ouvires uma criança dizer: "eu fazi um bolo", tu dirias que está certo ou errado? Por quê? Como corrigir? (Caso a resposta fosse "está errado").

Pode-se observar que, diante de perguntas como "Um flopo/segor/mafata pequeno/a é um/a...", encontraram-se os dados esperados (como "segorzinho"), palavras reais da língua, ligadas à semântica (como formiga para "flopo pequeno" e elefante para "flopo grande"), além de algumas respostas que evidenciaram uma relação fonológica com a palavra inventada (como "cegonha", "cego" e "semente" para "segor"). Para a palavra "flopo", obtiveram-se respostas como "flor" e "floresta"; e, para "mafata", a palavra "fada" apareceu algumas vezes.

A partir da observação dos diferentes tipos de resposta, além da incorporação de estudos da Psicologia Experimental, da Psicologia Cognitiva, além de pressupostos advindos da área da Aquisição da Linguagem, procedeu-se à reformulação e à expansão dos testes com que se pretendia trabalhar.

\section{4) A REELABORAÇÃO DOS TESTES}

Baseando-nos, principalmente, em alguns estudos de Eve Clark (1993, 2009, 2010) e de Goswami e Bryant (2007), além da observação de aspectos da Psicologia Cognitiva (MATLIN, 2004; STERNBERG, 2010), o teste de consciência morfológica e de consciência fonológica foram reformulados e/ou expandidos. Será explicitado o processo pelo qual se passou para chegar à versão atual deste material.

\section{1) O TRABALHO COM PSEUDOPALAVRAS}

Berko (1958) foi uma das pioneiras nos estudos sobre o conhecimento morfológico utilizando-se de pseudopalavras. A autora acreditava que, quando uma criança acrescenta, por exemplo, o "s" para formar o plural em uma palavra real da língua, não é possível saber se ela adquiriu a regra do plural ou se está apenas repetindo o que já foi ouvido antes. Porém, no momento em que a criança consegue acrescentar o sufixo de forma correta a uma pseudopalavra, isso revela que ela internalizou a regra e é capaz de generalizá-la aos contextos adequados. Em função das premissas formuladas por Berko, optou-se por manterem-se as pseudopalavras em algumas tarefas do teste.

Por outro lado, nos testes de Lorandi (2011a) pode-se observar que muitas respostas obtidas foram palavras reais da língua, em que a criança atribuiu um significado à nova palavra (por exemplo: para a pseudopalavra "mafata" viram-se

\footnotetext{
${ }^{5}$ Supergeneralizações de formas verbais irregulares, inovações lexicais e trocas de sufixos flexionais, tais como "fazi" em vez de "fiz", "massageira" em vez de "massagista" e "comei" em vez de "comi", respectivamente.
} 
respostas como "formiga"). A partir da reflexão acerca de por que a criança fornece palavras reais da língua em vez de utilizar a base dada (pseudopalavra), recorreu-se aos estudos de Eve Clark (2009) sobre a aquisição da linguagem, que mostram que o sentido desempenha um papel crítico na aquisição de novas palavras.

Segundo Clark (2009), ao se deparar com uma palavra nova, desconhecida, a criança precisa, primeiramente, compreender o sentido, criar uma representação que a ajude a reconhecer a nova palavra. Uma vez que ela adiciona significado, torna-se capaz de fazer julgamentos, para, então, produzir uma palavra.

Pensando nessas questões, decidiu-se por acrescentar nos testes imagens referentes a cada palavra e pseudopalavra, a fim de que o fator "falta de significado" não fosse um motivo para respostas inadequadas das crianças. Além disso, a inclusão de imagens tem por objetivo diminuir a demanda cognitiva da criança, uma vez que não precisa, além de manter em mente as informações com que precisa trabalhar, pensar em uma representação inventada para o significado da pseudopalavra. Então, juntamente à pseudopalavra "(imagem 1)", por exemplo, adicionou-se a imagem de um pássaro, que servirá como referência para a nova palavra.

Também em função da importância do significado na aquisição e produção de novas palavras, acrescentamos questões com palavras reais da língua.

Os testes, além de propiciar ao pesquisador a oportunidade de obtenção de dados de consciência linguística, também devem captar a atenção da criança, de modo que sua desatenção ou desinteresse também não sejam fatores intervenientes e que possam gerar respostas que não revelem seu conhecimento. Assim, procedeu-se à busca por entender como um teste pode ser aprazível à criança.

\section{2) OS JOGOS DE IMAGINAR NO DESENVOLVIMENTO COGNITIVO INFANTIL}

Desde muito cedo as crianças brincam, utilizando sua imaginação. Goswami e Bryant (2007) dizem que crianças menores tendem a brincar a partir de fatos aos quais são expostas no dia a dia, como, por exemplo, beber água em um copo vazio, fingindo estar cheio. Por volta de dois anos, as brincadeiras já se desvinculam do referencial, e a criança é capaz de fazer metarrepresentações (utilizando, por exemplo, uma banana como telefone). Essa brincadeira de inventar é uma das primeiras manifestações infantis acerca de sua capacidade de representação.

Ao recorrer à imaginação, a criança transcende o mundo real e desenvolve-se cognitivamente. Esse processo de metarrepresentação permite que ela inicie um processo de entendimento da própria cognição e dos pensamentos enquanto entidades.

Em uma brincadeira simbólica, o significado das coisas para a criança não depende do seu status como objetos reais no mundo perceptivo, mas do seu status no mundo imaginário. Por meio da brincadeira de "faz de conta", a criança está manipulando suas relações cognitivas para informação e tomando uma representação como o objeto da cognição (formando meta-representações, de acordo com Leslie, 1987) (GOSWAMI; BRYANT, 2007, p.12). ${ }^{6}$

\footnotetext{
${ }^{6}$ Tradução destas autoras para o original: In symbolic play, the meaning of things to the child depends not on their status as real objects in the perceptual world, but on their status in the imaginary world. Through pretend play, the child is manipulating her cognitive relations to information, and taking a representation
} 
Os autores afirmam, ainda, que os jogos normalmente precisam ser compartilhados, o que favorece o desenvolvimento de outras habilidades, como a teoria da mente, além do fato de que a linguagem torna-se fundamental para que haja a comunicação, a interação social, a brincadeira cooperativa e uma alta exigência imaginativa.

De modo a contemplar esses aspectos no teste de consciência morfológica, a primeira tarefa é uma história, em que a criança adentra em um cenário previamente preparado e é convidada a passear por uma cidade mágica, brincando de inventar palavras para situações diferentes que irão aparecendo. O objetivo é estimular a imaginação, a criatividade, deixar a criança à vontade, sem preocupar-se com o "certo" ou o "errado", proporcionando-lhe um ambiente descontraído para brincar com as palavras.

Além de ser divertido, atraente e oferecer oportunidades para que a criança revele seu conhecimento, um teste eficaz deve levar em consideração os diversos fatores cognitivos que entram em ação no momento da realização das tarefas com que lida. Para tanto, recorreu-se aos estudos da Psicologia Cognitiva e da Neurociência, descritos a seguir.

\section{3) O SUPORTE DA PSICOLOGIA COGNITIVA E DA NEUROCIÊNCIA}

Os estudos das Neurociências mostram que o córtex pré-frontal não está maduro na infância, área esta que é responsável pela atenção, pelo planejamento de ações, por algumas ações da memória de trabalho, pela tomada de decisões, entre outros (COSENZA; GUERRA, 2011; MATLIN, 2004; STERNBERG, 2010). Desse modo, tornou-se premente pensar em atividades que não sobrecarregassem a memória de trabalho ${ }^{7}$, além de uma diversidade de estímulos, de modo que a criança não precise manter o foco no mesmo tipo de atividade durante muito tempo.

Dessa maneira, os testes possuem diversos recursos que buscam despertar a atenção da criança, utilizando de cores, texturas e atividades diferentes em cada etapa, trabalhando sua imaginação e sua vontade de continuar engajada na brincadeira.

Outro fator importante para qualquer atividade que se for realizar é a motivação. As emoções possuem grande valor e influência em todas as áreas da vida humana, inclusive para o aprendizado. Segundo Cosenza e Guerra (2011), as emoções e a atenção estão intimamente relacionadas, o que permite que experiências fortemente ligadas à emoção ativem a vigilância e a motivação. Assim, os testes são pensados de maneira que haja interação e que a criança se sinta em uma brincadeira, e não sendo testada como se fosse uma prova da escola.

as the object of cognition (forming metarepresentations, Leslie 1987) (GOSWANI; BRYANT, 2007, p.12).

\footnotetext{
${ }^{7}$ Memória de trabalho é a memória transitória, em que uma informação é retida por um tempo não muito longo, podendo tornar-se, posteriormente, uma memória de longa duração ou ser descartada. (COSENZA; GUERRA, 2011; IZQUIERDO, 2011).
} 


\section{5) RESULTADOS}

Nesta seção, apresentar-se-ão amostras de cada uma das seis tarefas elaboradas para o teste de consciência morfológica, além de questões do teste de consciência fonológica, seguidas de uma explanação sobre a importância de se tomar como referência um modelo teórico eficiente para a elaboração de tarefas que gerem dados de consciência linguística.

\section{1) A REELABORAÇÃO E EXPANSÃO DOS TESTES}

Para a reelaboração do teste de consciência morfológica, além dos subsídios já expostos, procurou-se também abordar diversas questões de ordem morfológica, de modo a desenvolver um teste que fosse bastante abrangente nesse sentido. Foram pensadas questões sobre: flexão (de gênero - feminino e masculino; de número singular e plural), derivação (formação de agentivos, adjetivos, locativos, diminutivo, aumentativo e de verbos (por analogia ${ }^{8}$, a partir de nomes)). Vale explicar que, do primeiro teste para o atual, mantiveram-se tarefas do Teste 1 e do Teste 3 , mas as do Teste 2 foram retiradas por terem sido entendidas como muito difíceis para o públicoalvo já no trabalho de 2011a. O teste atual foi aplicado a 78 crianças, com idades entre 4:0 e 11:3.

Antes de iniciar as tarefas do Teste de Consciência Morfológica (TCM), as crianças realizaram um pré-teste, com o objetivo de: a) habituarem-se à brincadeira de inventar palavras e b) permitir que os pesquisadores observassem se os participantes eram capazes de entender as tarefas, de modo que o não entendimento não fosse uma variável interveniente nos resultados posteriores. As questões do pré-teste são as que seguem.

\section{(4) Pré-teste do TCM}

Nós vamos brincar agora de adivinhar que palavra é. Observa as figuras que eu vou te mostrar e responde ao que vou te perguntar.

Imagem $^{9}$ - uma bola, uma bolona e uma bolinha.

Perguntas:

1) aqui tem uma bola, aqui tem uma bolona e aqui tem uma Imagem - uma bola de um lado e várias bolas de outro.

2) aqui tem uma bola, aqui tem várias

Imagem - uma meluca, uma melucona, uma meluquinha.

Para essa bola diferente eu inventei o nome de "meluca".

Pergunta:

3) aqui tem uma meluca, aqui tem uma melucona e aqui tem uma

Imagem - uma meluca de um lado e várias melucas de outro.

4) aqui tem uma meluca, aqui tem várias

\footnotetext{
${ }^{8} \mathrm{O}$ uso desse tipo de tarefa, realizada por meio de analogia, tem inspiração no trabalho de Nunes e Bryant (2006).

${ }^{9}$ As imagens encontram-se em anexo.
} 
Vou fazer outra pergunta. Presta atenção!

Imagem - um menino e uma menina.

Pergunta:

5) aqui tem uma menina. Aqui tem um

Imagem - uma mifarra e um mifarro.

Para esse bichinho diferente eu inventei o nome de "mifarra".

Pergunta:

6) se aqui eu tenho uma mifarra, aqui eu tenho um

No pré-teste encontram-se questões sobre flexão de número e de gênero, além de questões sobre a derivação para o diminutivo. Essas questões foram consideradas como sendo de mais fácil domínio, tanto devido a evidências da aquisição da linguagem, visto que são estruturas adquiridas em idade tenra, como também pelo fato de que aparecerão em tarefas posteriores. $\mathrm{O}$ fato de ter começado por questões mais fáceis também objetiva ser um fator motivacional para a criança, uma vez que, se encontrasse dificuldades já no início do teste, poderia não querer seguir realizando as atividades. Isso foi um aspecto especialmente pensado para as crianças mais novas da amostra, as da Pré-escola I, que, no trabalho de Lorandi (2011a) apresentaram maior resistência ao teste.

A primeira tarefa do TCM é, como já mencionado, uma história, em que a criança é convidada a participar ativamente, podendo interagir com o cenário elaborado e com o experimentador, que a acompanhará em uma brincadeira de inventar palavras, e a criança fará isso quando for necessário, ao longo do trajeto que é percorrido. A história inicia da seguinte maneira:

\section{(5) Início da Tarefa 1 do TCM}

Pesquisador: Eu vou te convidar a passear por uma história, que tu vais ajudar a construir. Nessa história a gente vai deixar a imaginação livre e brincar de inventar algumas palavras. Vamos lá?

Vou te contar a história desse menino que gosta muito de viajar (imagem). Ele viaja por muitos lugares diferentes, até que um dia chegou a essa cidade mágica, diferente de tudo que conhecemos! Agora tu também vais conhecê-la! Quando ele chegou, o dia estava lindo; o céu, cheio de nuvens que parecem algodão, como essas (apontar painel). Tu viste que tem nuvens grandes e pequenas? Uma nuvem pequena é uma nuvenzinha. E uma nuvem grande é uma Resposta da criança (aumentativo 1).

$\mathrm{Na}$ Tarefa 1, a criança percorre o cenário com o pesquisador, respondendo às questões feitas, as quais envolvem a produção de palavras inventadas a partir de palavras reais da língua. $\mathrm{O}$ conhecimento morfológico envolvido nas questões aborda a flexão de número e a derivação de aumentativo, diminutivo, agentivo e locativo, além da formação de adjetivo. Para cada uma das questões, há um painel com uma descrição da cena. A história é curta, para que a criança crie o gosto pela brincadeira de inventar palavras sem cansar-se, mantendo-se motivada e interessada. 
Para a Tarefa 2, manteve-se o teste de Lorandi (2011a), de acrescentar sufixos e prefixos a pseudopalavras, a fim de verificar o conhecimento da criança sobre a própria língua. Acrescentaram-se tarefas de flexão ao teste e trocou-se uma palavra, em função de sua estrutura ${ }^{10}$.

(6) Primeira parte da Tarefa 2 do TCM

Estás vendo esta borboleta bonita (imagem)? Eu inventei um nome para ela! É uma gulana. Agora:
A. Uma gulana pequena é uma
B. Uma gulana grande é uma
C. Uma gulana menino é um
D. Aqui há uma gulana. Aqui há duas
E. Uma pessoa cheia de gulana está
F. Um lugar que vende gulana é um
G. Quem faz gulana é um

As pseudopalavras da Tarefa 2 são "flopo", "segor" e "gulana". "Flopo" e "segor" são palavras criadas no gênero masculino, sendo que a primeira tem acento na sílaba paroxítona e apresenta um encontro consonantal na primeira sílaba, e a segunda apresenta acento na sílaba oxítona e uma coda na segunda e última sílaba. O objetivo da formação de pseudopalavras com essa estrutura foi verificar se haveria influência nos tipos de sufixos escolhidos para as respostas. A outra pseudopalavra é "gulana", que, por sua vez, está no gênero feminino, com acento na sílaba paroxítona, padrão mais comum do português brasileiro. Além disso, conta com três sílabas, diferentemente das duas primeiras palavras. Para cada uma das palavras há sete questões, envolvendo flexão de número e gênero e derivação de diminutivo, aumentativo, locativo, agentivo e formação de adjetivo. Acreditou-se que esse número de questões seria o suficiente para abranger uma amostra significativa de seu conhecimento morfológico sem fatigar a criança, que ainda tem mais tarefas a responder.

$\mathrm{Na}$ Tarefa 3, pensando na importância ressaltada por Clark (2009) de adicionar um significado a uma nova palavra, optou-se por trabalhar com radicais conhecidos do $\mathrm{PB}$, com a proposta de adicionar sufixos em palavras que, no uso comum da língua, não seriam utilizados, como, por exemplo: brisa + ria $=$ brisaria, como sendo o lugar que vende brisa.

As questões são as mesmas feitas com pseudopalavras, para fins de posterior comparação.

(7) Primeira parte da Tarefa 3 do TCM

Vamos inventar mais um pouco? A palavra é sabor (imagem):
A. Um sabor pequeno é um
B. Um sabor grande é um

\footnotetext{
${ }^{10}$ A palavra "mafata" do teste de Lorandi (2011a) foi trocada por "gulana". O template é o mesmo, todavia algumas crianças estavam confundindo o início da palavra "mafata" com o artigo indefinido "uma", causando alterações na base.
} 
C. Um sabor menina é uma

D. Aqui há um sabor. Aqui há dois

E. Uma pessoa cheia de sabor está

F. Um lugar que vende sabor é uma

G. Quem faz sabor é um

As palavras utilizadas nessa Tarefa foram "sabor", "brisa" e "espuma", as quais foram escolhidas por não serem muito frequentes no vocabulário infantil e por permitirem a criação de novas palavras, como suas versões no masculino ou no feminino.

Amparados pelos testes desenvolvidos por Karmiloff-Smith e seus colegas (1979, 1996), buscou-se avaliar o conhecimento morfológico das crianças por meio de acesso consciente não apenas via tarefas de produção, mas também por meio da identificação da resposta mais adequada. Entende-se que, em alguns casos, a produção da resposta possa ser mais difícil do que sua identificação, por envolver demandas cognitivas diferentes. Enquanto para produzir é preciso buscar uma informação em seu repertório lexical, trabalhar com ela, para, então, emitir uma resposta, na identificação apenas é preciso comparar o conhecimento apresentado com o seu conhecimento, para então, apontar a resposta que mais se adequa. Nessa Tarefa 4 a criança deve proceder à identificação de sufixos, com o auxílio de imagens. O objetivo é perceber se a criança consegue entender o significado do sufixo.

(8) Primeira parte da Tarefa 4 do TCM

Agora eu vou dizer uma frase e vou te dar três palavras para escolheres:

Enquanto o menino passeava, derramou leite no duende. O pobre duende ficou todo:
a) Leitinho
b) Leitado
c) Leites

Para as questões de identificação do sufixo adequado também foram utilizadas palavras reais da língua. A criança que ainda não possui esse conhecimento ou não consegue acessá-lo conscientemente poderá ter dúvidas e/ou dificuldades. As opções de respostas envolvem sufixos relacionados ao conhecimento morfológico já testado nas tarefas anteriores. Procurou-se também aproveitar a temática da história (Tarefa 1) na maioria das questões, de modo que fizesse sentido à criança.

A Tarefa 5 propõe a formação de verbos, na busca por perceber os processos utilizados pelas crianças no que diz respeito ao acréscimo de sufixos verbais a nomes.

(9) Primeira parte da Tarefa 5 do TCM

Vê o que eu vou te dizer e faz igual:

Quem gosta de usar a caneta vai: canetar. Agora é a tua vez:

A. Quem gosta de usar a bolsa vai:

B. Quem gosta de usar o papel vai: 
A Tarefa 5 envolve seis questões. Entende-se que, em termos de quantidade de respostas, não é uma tarefa muito expressiva, todavia acredita-se que é possível depreender o conhecimento da criança sobre sufixos verbais e derivação de verbos a partir de nomes. Também em função da quantidade de tarefas no TCM, buscou-se reduzir o número de questões.

Para finalizar, na Tarefa 6, é apresentado à criança um ET chamado Zoki, que vem de um planeta diferente e que, portanto, não sabe o significado de algumas palavras. A tarefa, então, tem dois propósitos: a) o julgamento de aceitabilidade, em que a criança deve dizer se a afirmação do ET está certa ou errada, e b) a explicação de por que ela entende que está certo ou errado.

(10) Primeira parte da Tarefa 6

Vamos brincar um pouco de ser professor? Esse ET é o Zoki. Ele veio de um planeta distante, chamado Árion, e ainda não sabe algumas palavras; outras ele sabe bem. Vamos ajudá-lo a entender as palavras?

A. O Zoki disse que uma lua pequena é uma luona. Isso está certo? Por quê?

B. Ele disse também que uma casa grande é um casarão. Isso está certo? Por quê?

Essa tarefa apresenta dez questões ${ }^{11}$, que também envolvem o conhecimento morfológico presente nas questões anteriores. Destaca-se que, nessa tarefa, a criança precisa, além de acessar conscientemente seu conhecimento, de modo a julgar a aceitabilidade do que o ET está dizendo, explicar sua opinião, ou seja, é preciso que elabore seu conhecimento de modo a explicá-lo, algo que, de acordo com o modelo RR, só é possível quando as representações na mente da criança atingem o nível Explícito 3.

Todas as tarefas apresentadas tem como objetivo avaliar o nível Explícito 2, em que é possível, devido ao formato das representações, acessar conscientemente o conhecimento. Apenas na última tarefa são requeridas habilidades que envolvem representações de nível Explícito 3. Ao final, o TCM apresenta 72 questões que avaliam o nível E2 e 10 para o nível E3.

Com relação ao nível Explícito 1, entende-se que as crianças cujas representações referentes ao seu conhecimento morfológico ainda estejam nesse nível possam dar respostas que não sejam as esperadas para o nível Explícito 2, mas que demonstrem uma sensibilidade aos recursos morfológicos da língua, como por exemplo, expressando noções de diminutivo e de aumentativo por meio do tamanho dos animais, quando vai fornecer resposta para "um flopo pequeno" e "um flopo grande", por exemplo, com "formiga" e "elefante", respectivamente. Nesse caso, a criança está manifestando conhecimento das noções de pequeno e grande, envolvidas no diminutivo e no aumentativo, mas sem utilizar-se de recursos morfológicos como sufixos, uma vez que não acessa conscientemente esse conhecimento ainda.

\footnotetext{
${ }^{11}$ Procurou-se investir mais nesse tipo de questão, dada sua relevância. Eram 4 no primeiro teste de consciência morfológica e são 10 no teste atual.
} 
Outro aspecto importante de ser ressaltado e que tem origem na Psicologia Experimental, é que a ordem das questões foi variada aleatoriamente, para que pudessem ser avaliadas pelo conhecimento que averiguam e não pela ordem em que foram apresentadas. Evita-se, desse modo, que uma determinada questão apresente maior percentual de inadequação de respostas, por exemplo, simplesmente por ser a primeira a ser testada.

Para o teste de consciência fonológica (Moojen et al., 2003), foram acrescentadas seis questões que pudessem avaliar o nível Explícito 3, uma vez que o teste não prevê explicação verbal de respostas. O tipo de questão acrescentada teve inspiração no trabalho de Fontoura e Lorandi (2015). O teste apresenta 70 questões do que consideramos nível E2 e 6 para o nível E3. A seguir exemplificar-se-ão questões do teste e também a tarefa acrescentada neste estudo.

(11) Exemplo de questão do CONFIAS para o nível da sílaba

Que desenho é esse? (Mostra o desenho de uma cobra). Agora vou te dizer três palavras e uma delas começa como "cobra". Diz qual é.

Copo - time - loja.

(12) Exemplo de questão do CONFIAS para o nível do fonema

Que desenho é esse? (Mostra o desenho de um sino). Agora vou te dizer três palavras e uma delas começa com o mesmo som de "sino". Me diz qual é.

Sede - chuva - gema

(13) Exemplo de questão acrescentada ao CONFIAS para o nível da sílaba

Eu tenho as palavras "massa" e "mala" (imagens). Essas palavras são parecidas, certo? São parecidas porque têm sons quase iguais. Mas elas têm uma diferença nos sons. Sabes qual é? Explica para mim.

(14) Exemplo de questão acrescentada ao CONFIAS para o nível do fonema

Eu tenho as palavras "uva" e "luva". Essas palavras são parecidas, certo? São parecidas porque têm sons quase iguais. Mas elas têm uma diferença nos sons. Sabes qual é? Explica para mim.

A seguir serão trazidas algumas respostas ao TCM, de modo especial destacando a importância de se levar em consideração um modelo como o de Redescrição Representacional não só como fundamentação para as noções de consciência linguística e seu desenvolvimento, mas também como amparo para se pensar a metodologia para aquisição de dados.

\section{2) ALGUMAS CONSIDERAÇÕES SOBRE OS NÍVEIS E2 E E3 NOS TESTES}

Conforme apontado no início deste artigo, decisões sobre o que pode ser considerado como indício de consciência linguística deve perpassar a noção de 
consciência que se aborda, a qual, por sua vez, só pode ser concebida a partir de um modelo teórico eficaz. Este estudo, a partir do modelo RR, entende a consciência linguística como uma habilidade possível a partir do momento em que o conhecimento adquirido encontra-se em níveis de representação mental em que é possível o acesso explícito e consciente a esse conhecimento, além da possibilidade, em um desses níveis, da elaboração verbal sobre o conhecimento. Desse modo, ao contrário de outros modelos, é possível que diferentes formas de explicitação do conhecimento possam ser consideradas indícios de consciência - da sensibilidade à explicitação verbal.

O gráfico abaixo mostra a diferença entre os níveis de representação mental E2 e E3 alcançados pelas crianças nas diferentes séries. Os dados foram calculados em termos de porcentagens para fins de comparação.

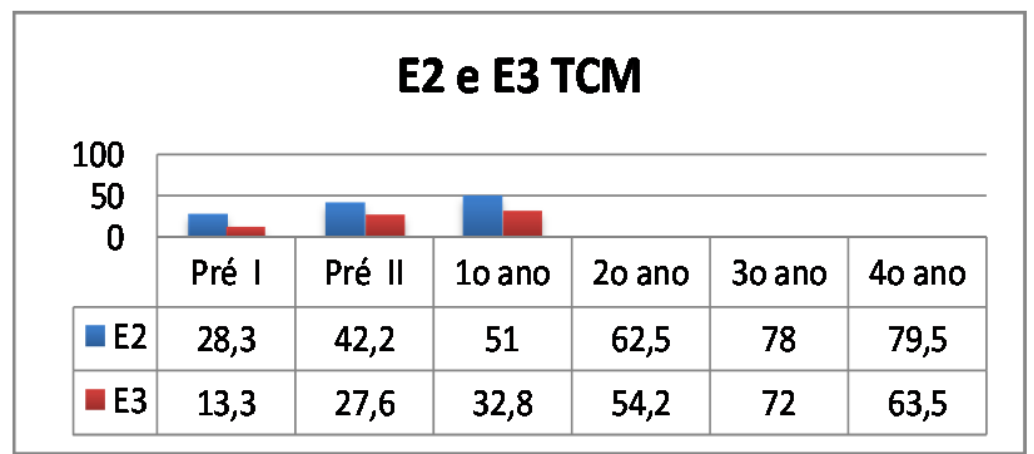

Gráfico 1: Diferença entre níveis E2 e E3 nas séries avaliadas - TCM Fonte: os autores.

O Gráfico 1 mostra que há uma evolução em termos de respostas adequadas da Pré-escola $\mathrm{I}$ ao $3^{\circ}$ e $4^{\circ}$ anos, sendo que, nessas últimas, praticamente não há diferença. Todavia, de modo especial nas primeiras séries, é visível que há mais respostas adequadas para o nível E2 do que para o E3, o que revela que há uma diferença entre prover uma resposta em que se acesse conscientemente o conhecimento e uma resposta em que se possa explicar o conhecimento acessado. Vejam-se os resultados para as questões referentes ao CONFIAS no Gráfico 2.

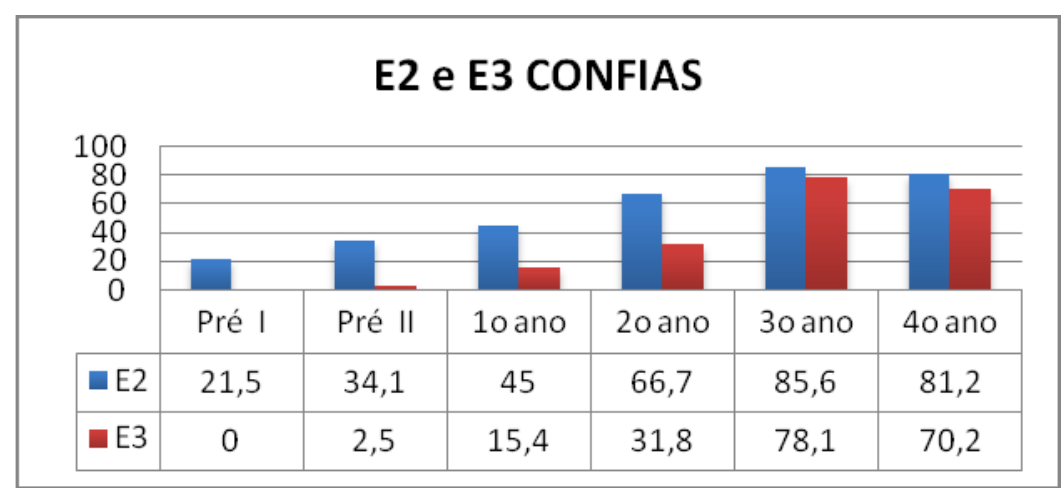

Gráfico 2: Diferença entre níveis E2 e E3 nas séries avaliadas - CONFIAS Fonte: os autores.

Para o CONFIAS também é possível perceber uma evolução das crianças mais novas para as crianças mais velhas. Entretanto, a diferença entre as questões de nível E3 
entre os diferentes testes é mais acentuada que em nível E2 de Pré-escola I ao $2^{\circ}$ ano. Para os $3^{\circ}$ e o $4^{\circ}$ anos, o nível E3 no CONFIAS supera o do TCM.

Destaca-se também que a aplicação do CONFIAS fora dividida em duas etapas, uma vez que as crianças mostraram-se cansadas após a aplicação das tarefas referentes à sílaba. O TCM e o CONFIAS, entretanto, apresentam praticamente o mesmo número de tarefas, o que parece indicar que os esforços no sentido de tornar o TCM mais aprazível alcançou o êxito almejado.

Os dados apresentados sobre os dois testes mostram-se importantes em, pelo menos, dois sentidos. Tomando a discussão levantada anteriormente, se a noção de consciência linguística adotada não prevê a diferença entre os níveis E2 e E3, considerando que apenas o acesso consciente já é sinal de consciência ou que apenas quando a criança consegue falar sobre o seu conhecimento é que ela está consciente do mesmo, perde-se a sutileza do desenvolvimento desse fenômeno e também aspectos importantes sobre como funciona a mente com relação à consciência sobre a língua. $\mathrm{O}$ segundo aspecto relevante mostra que: a) o longo dos anos a diferença entre E2 e E3 diminui, confirmando, possivelmente, que essa é uma questão de desenvolvimento de habilidade diferentes, como revela o modelo RR, e b) as diferenças apresentadas entre consciência fonológica e consciência morfológica pode ser um resultado da forma como esses subsistemas são abordados na escola, uma vez que, durante o processo de alfabetização, há uma tendência em se mudar o foco do nível linguístico da palavra, domínio da morfologia, para o nível da sílaba e, principalmente, do fonema, domínios da fonologia, o que poderia motivar a redescrição do nível E2 para o nível E3 entre o $2^{\circ}$ e o $3^{\circ}$ ano.

Também é importante ressaltar que as crianças começam com um desempenho melhor em consciência morfológica, tanto em nível E2 quanto em E3, o que pode ter implicações importantes sobre: a) o desenvolvimento da consciência linguística em

subsistemas diferentes e/ou b) as reformulações propostas no TCM podem ter sido realmente eficazes e terem envolvido mais as crianças, que, por sua vez, por sentirem-se envolvidas e por estarem respondendo a tarefas que levam em consideração aspectos como memória, atenção e motivação, podem ter apresentado um melhor resultado. Essas questões só podem ser mais esclarecidas com testes equivalentes nesses pontos.

\section{6) CONSIDERAÇÕES FINAIS}

Muitos artigos desenvolvidos no Brasil parecem partir da premissa de que o conceito do que vem a ser consciência linguística é um ponto pacífico e, portanto, prescinde de ser explicitado. Contudo, a consciência continua, desde os primórdios da filosofia grega, sendo um dos temas preferidos, especialmente nas áreas da Filosofia, da Psicologia Cognitiva e das Neurociências (DEHAENE, 2015), o que indica que, no âmbito dos estudos sobre a linguagem não poderia ser diferente.

Não só em termos de teoria a noção de consciência linguística precisa ser abordada com profundidade, mas também em termos de metodologia. Com o avanço das técnicas de neuroimagem, a preocupação com questões metodológicas tem ganhado (ou retomado) amplo espaço em meio às discussões da academia. 
O presente estudo mostrou a reformulação de um teste de consciência morfológica, o TCM, que fora inspirado no trabalho de Lorandi (2011a) e que se amparou em estudos multidisciplinares para alcançar seus objetivos. É um primeiro passo rumo ao aprimoramento da metodologia para a obtenção de dados que sejam considerados mais confiáveis em termos de consciência morfológica e que também sejam capazes de evidenciar processos mentais importantes com relação ao fenômeno que representam. Também mostrou a ampliação de um teste já validado para a consciência fonológica, mas que carecia de questões que abordassem todos os níveis considerados na perspectiva teórica adotada neste trabalho, o modelo RR. Os resultados mostram que as adaptações realizadas parecem ter surtido o efeito esperado, uma vez que as crianças mostraram-se mais envolvidas com o TCM que com o CONFIAS, apresentando, inclusive, melhores resultados e menor nível de fadiga, de modo especial, nas séries iniciais. Salienta-se, entretanto, que o melhor desempenho no TCM do que no CONFIAS ainda precisa ser estudado com mais rigor, com testes equivalentes nos aspectos cognitivos que foram trabalhados no TCM.

Por fim, destaca-se que o fato de abordarem-se diferentes níveis de representação mental de consciência linguística apresentou-se de fundamental relevância, uma vez que, em termos de nível E2, a diferença entre TCM e CONFIAS não é tão saliente quanto o que se observou nas questões de E3. É possível que a redescrição para o nível E3 em termos de consciência fonológica dependa da mudança de foco no ensino - do nível da palavra para o nível de unidades menores, como o fonema, como se observou na diferença de desempenho entre o $2^{\circ}$ e o $3^{\circ}$ ano. Também se pode depreender dos resultados que a morfologia e a fonologia, no tocante à consciência em nível E2 e E3, possam seguir caminhos levemente distintos, uma vez que a consciência morfológica parece desenvolver-se antes que a consciência fonológica e que mesmo crianças na Pré-escola I, com idades entre 4 e 5 anos, puderam mostrar seu conhecimento tanto em nível E2 quanto em nível E3 para a consciência morfológica, mas não necessariamente para a consciência fonológica, pelo menos em nível E3.

\section{REFERÊNCIAS}

BERKO, J. The child's learning of English morphology. Word, 14, p. 150-177, 1958.

CLARK, E. V. Awareness of language: some evidence from what children say and do. In: SINCLAIR, A.; JARVELLA, R. J.; LEVELT, W.J. (editors). The child's conceptions of language. Berlim: Springer-Verlag, 1978. p. 17-44.

CLARK, E. V. The lexicon in acquisition. Cambridge: Cambridge University Press, 1993.

CLARK. E. V. Coining new words: Old and new word forms for new meanings. MENN, L.; RATNER, B. N. (Eds). Methods for Studying Language Acquisition. London: Laurence Erlbaum Associates, 2009.

CLARK, E. V. First Language Acquisition. 2nd ed. Cambridge: Cambridge University Press, 2010.

COSENZA, R. M.; GUERRA, L.B. Neurociência e Educação: como o cérebro aprende. Porto Alegre: Artmed, 2011. 
GOSWAMI, U.; BRYANT, P. Children's Cognitive Development and Learning (Primary Review Research Survey 2/1a), Cambridge: University of Cambridge Faculty of Education, 2007.

KARMILOFF-SMITH, A. A Functional Approach to Child Language. Cambridge University Press, 1979.

KARMILOFF-SMITH, A. From meta-processes to conscious access: Evidence from children's metalinguistic and repair data. Cognition, 23 p. 95-147,1986.

KARMILOFF-SMITH, A. Beyond Modularity: a developmental perspective on cognitive science. Cambridge (MA): MIT, 1992. 234 p.

KARMILOFF-SMITH, A. Précis of Beyond modularity: A developmental perspective on cognitive science. Behavioral and Brain Sciences, 17, p. 693-745, 1994.

KARMILOFF-SMITH, A. Development itself is the key to understanding developmental disorders. Trends in Cognitive Sciences, 2 (10), 389-398,1998.

KARMILOFF-SMITH, A. From Constructivism to Neuroconstructivism: The ActivityDependent Structuring of the Human Brain. In: Marti, E. Rodríguez, C. After Piaget. New Brunswick, N. J.: Transaction Pub, 2012.

KARMILOFF-SMITH, A.; GRANT, J.; JONES, M. C.; CUCLE, P. Rethinking metalinguistic awareness: Representing and accessing knowledge about what counts as a word. Cognition, 58, p. 197-219, 1996.

LORANDI, A. Formas Morfológicas Variantes na gramática infantil: um estudo à luz da Teoria da Otimidade. 2006. 185 p. Dissertação (Mestrado em Letras) Faculdade de Letras, Pontifícia Universidade Católica do Rio Grande do Sul, Porto Alegre, 2007.

LORANDI, A. From sensitivity to awareness: the morphological knowledge of Brazilian children between 2 and 11 years old and the representational redescription model. 2011. Tese (Doutorado em Letras) - Faculdade de Letras, Pontifícia Universidade Católica do Rio Grande do Sul, Porto Alegre, 2011 a.

LORANDI, A. A consciência linguística e o modelo de Redescrição Representacional: como explicar a discrepância entre os processos de consciência em diferentes microdomínios?. In: FERREIRA GONÇALVES, G; BRUM DE PAULA, M. R.; KESKE-SOARES, M. (Org.). Estudos em Aquisição Fonológica. Pelotas: Editora e Gráfica Universitária PREC-UFPel, 2011, v. 4. 2011b. p. 205-218.

LORANDI, A. KARMILOFF-SMITH A. From sensitivity to awareness: the morphological knowledge and the Representational Redescription Model. Letras de Hoje, Porto Alegre, v. 47, n. 1, p. 6-16, jan./mar. 2012.

LORANDI, A. ; MENEZES, J. T. ; SILVA, I. L. ; SILVA, L. B. ; MARQUES, D. M. Consciência linguística: diferentes olhares. Letrônica, v. 5, p. 21-44, 2013.

LORANDI, A.; KARMILOFF-SMITH, A. A consciência morfológica e o modelo de Redescrição Representacional. In: C. L. P.; L. C. S. (Org.). ISIAL : anais do I Seminário Internacional de Aquisição da Linguagem. 1ed. Porto Alegre: EDIPUCRS, v. 1, p. 1-18, 2014.

FONTOURA, M. E.; LORANDI, A. Subsídios teórico-práticos para o desenvolvimento de testes de consciência linguística voltados à população autista. In: TEIXEIRA, I. F.; 
SANTOS, S. M.; FERNANDES, C. (Orgs.) Estudos sobre Leitura e Escrita. Florianópolis: Bookess, 2015. p. 368-418.

MOOJEN, S. et al. ConsciênciaFonológica-Instrumento de Avaliação Sequencial (CONFIAS). Casa do Psicólogo, 2003.

NUNES, T.; BRYANT, P. Improving literacy by teaching morphemes.London: Routledge, 2006. 202 p.

PRATT, C.; GRIEVE, R. The development of metalinguistic awareness: An introduction. In: Metalinguistic awareness in children. Springer Berlin Heidelberg, 1984. p. 2-11.

SLOBIN, D. I. A case study of early language awareness. In: The child's conception of language. Springer Berlin Heidelberg, 1978. p. 45-54.

TUNMER, W. E.; HERRIMAN, M. L. The development of metalinguistic awareness: a conceptual overview. In: TUNMER, W. E.; PRATT, C.; HERRIMAN, M. L. (editors). Metalinguistic awareness in children: theory, research and implications. Berlim: Springer-Verlag, 1984, p. 12-35.

\section{ANEXOS}

Imagem 1: pássaro segor
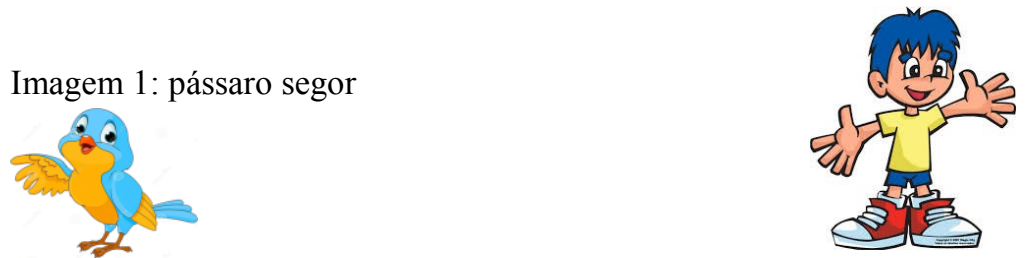

Imagem 2: bola

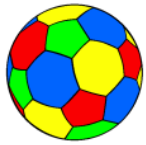

Imagem 3: meluca
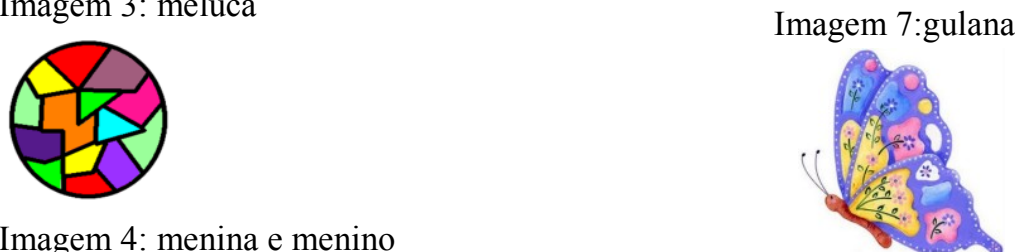

Imagem 4: menina e menino

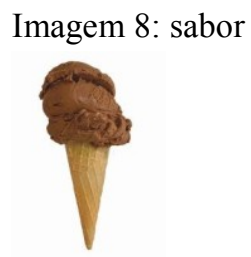

Imagem 5:mifarra e mifarro

Imagem 9: Zoki
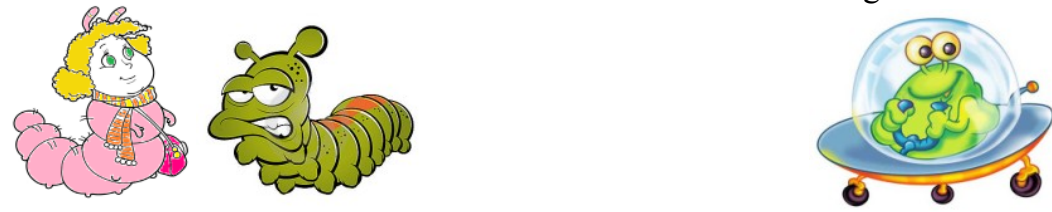

Imagem 6: menino da Tarefa 1 